\title{
Integrated water resource assessment for the Adelaide region, South Australia
}

\author{
James W. Cox ${ }^{1,3}$, Michele Akeroyd ${ }^{2}$, and Danielle P. Oliver ${ }^{2,4}$ \\ ${ }^{1}$ South Australian Research and Development Institute, Adelaide, 5064, Australia \\ ${ }^{2}$ Goyder Institute for Water Research, Adelaide, 5001, Australia \\ ${ }^{3}$ The University of Adelaide, Adelaide, 5001, Australia \\ ${ }^{4}$ CSIRO Land and Water, Adelaide, 5064, Australia \\ Correspondence to: James W. Cox (jim.cox@sa.gov.au)
}

Published: 17 October 2016

\begin{abstract}
South Australia is the driest state in the driest inhabited country in the world, Australia. Consequently, water is one of South Australia's highest priorities. Focus on water research and sources of water in the state became more critical during the Millenium drought that occurred between 1997 and 2011. In response to increased concern about water sources the South Australian government established The Goyder Institute for Water Research - a partnership between the South Australian State Government, the Commonwealth Scientific and Industrial Research Organisation (CSIRO), Flinders University, University of Adelaide and University of South Australia. The Goyder Institute undertakes cutting-edge science to inform the development of innovative integrated water management strategies to ensure South Australia's ongoing water security and enhance the South Australian Government's capacity to develop and deliver science-based policy solutions in water management. This paper focuses on the integrated water resource assessment of the northern Adelaide region, including the key research investments in water and climate, and how this information is being utilised by decision makers in the region.
\end{abstract}

\section{Introduction}

Historically, South Australia has relied on three raindependent sources of water - the River Murray, Mt. Lofty Ranges catchment and groundwater. However, like much of the southern regions of the continent, many areas of South Australia have experienced a decline in surface water flows and groundwater levels over the past decade compared to long term averages (CSIRO, 2007). This has resulted in an increased threat to the security of water supplies for regional communities, industry and the environment. In the future the pressure on these sources of water is expected to increase with a decrease in average annual rainfall in the northern Adelaide region of approximately $8-14 \%$. At the same time, South Australia's population is expected to grow from the current 1.67 million people to reach 1.79 million by 2016 and 2.28 million by 2036 (Government of South Australia, 2015), increasing the demand on water supplies.
To combat this threat, the State established The Goyder Institute for Water Research - a partnership between the South Australian State Government, the Commonwealth Scientific and Industrial Research Organisation (CSIRO), Flinders University, University of Adelaide and University of South Australia. The Goyder Institute undertakes cutting-edge science to inform the development of innovative integrated water management strategies to ensure South Australia's ongoing water security and enhance the South Australian Government's capacity to develop and deliver science-based policy solutions in water management.

There are a number of key research investments that have been targeted to inform integrated water management in State Government water planning and policy development. This new science will be presented in the context of the government policy and development drivers, with a focus on several key research issues. 


\section{Background}

\subsection{Northern Adelaide Plains region}

Horticultural production in the Virginia area of the Northern Adelaide Plains (NAP) (Fig. 1) has been developed utilising a good supply of groundwater for irrigation (Stevens, 2004). However, the long-term supply of this water has been threatened due to total pumping volumes exceeding the total recharge (Anon, 1995). This has led to the utilisation of reclaimed water (reclaimed sewage effluent) as a water source for agriculture in the region. The Virginia Triangle is now one of the largest Class A water reclamation and reuse schemes in the world (Stevens, 2004). The South Australian Government would like to see the agricultural production area extended as shown in Fig. 2. The extension of agricultural production in this area would require identification of future water sources and an understanding of the quality and quantity of these sources.

\subsection{Water resources research}

There are a number of key research investments that have been targeted to inform integrated water management in State Government water planning and policy development. This new science will be presented in the context of the government policy and development drivers, with a focus on the following key research areas.

\subsubsection{Adelaide Plains groundwater}

This project has built upon existing knowledge to provide a thorough assessment of the groundwater resources beneath Adelaide, the capital city of South Australia, and the impacts of current and future extraction and climate change. It is the first study to provide an integrated assessment of the groundwater resources of the entire Adelaide metropolitan region.

\subsubsection{Optimal water resources mix}

A key product of this project is the development of methods for determining trade-offs between the multiple objectives of water security, economic efficiency and environmental benefits of water supply options that are consistent with the city's social values. The trade-offs analysis methodology developed also provided a framework that could be applied to other cities/regions to inform the development of total water cycle management plans.

\subsubsection{Managed aquifer recharge and stormwater use options}

This project assessed a range of potential uses of stormwater including via managed aquifer recharge at various locations around Australia and overseas. The project addressed

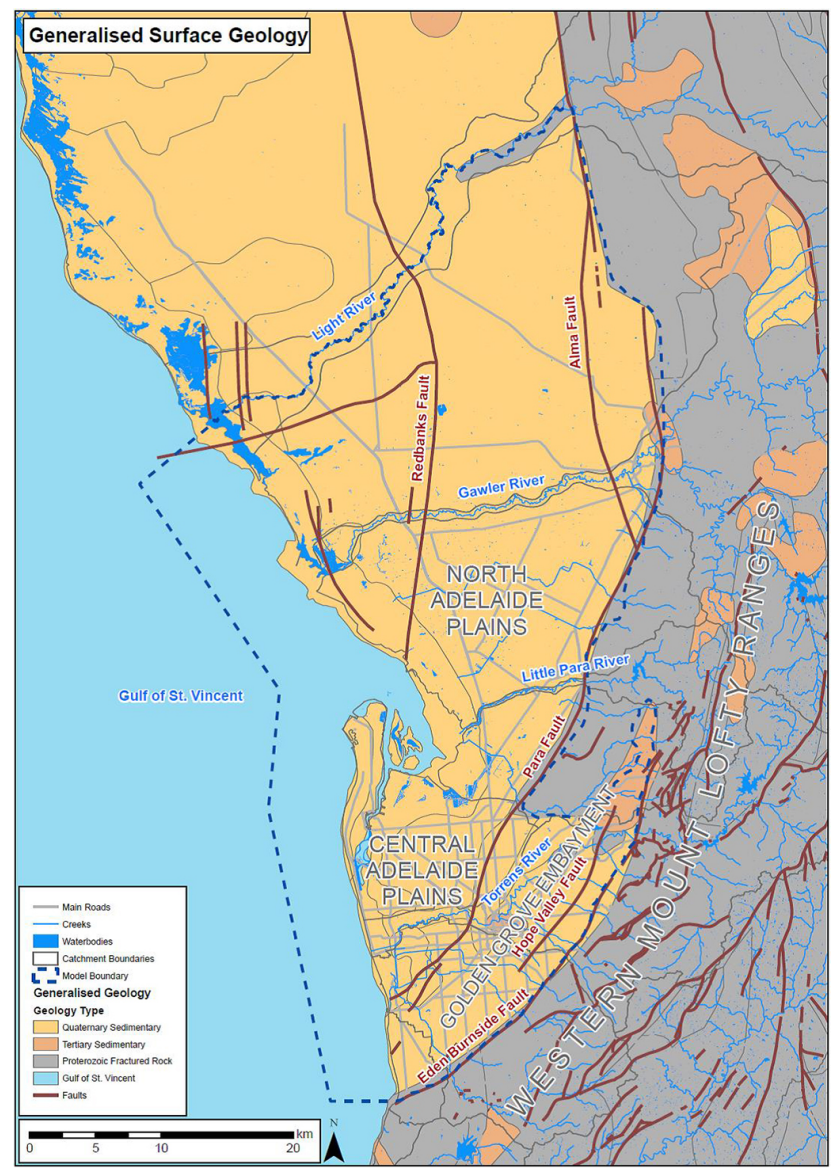

Figure 1. Map indicating the Northern Adelaide Plains region (from Bresciani et al., 2015a).

the health risk assessment of uses for public open space irrigation, third pipe non-potable supplies to households and industry and for drinking water supplies. For several of those uses prototype risk management plans were developed. The economics of some specific options were also considered taking account of environmental impacts, and surveys of public acceptance of the more novel options that were considered.

\subsubsection{Mt. Lofty Ranges catchment}

The Mt. Lofty Ranges catchments are the source of surface water for Adelaide reservoirs. This project built on existing knowledge, management and monitoring systems in the Mt. Lofty Ranges to understand environmental water needs, patterns of flow and water quality within the catchment. To support decision making, a tool has been developed that brings together all the information needed to make robust decisions on water allocations and assess the potential outcomes of alternative management options. The research has also involved collecting important hydro-ecological data and water quality assessments that support development of water allocation plans for the region, including installing monitoring 
equipment in high priority regions to measure water flow and quality and the subsequent ecological response from fish, vegetation and macro-invertebrates.

\subsubsection{SA Climate Ready}

SA Climate Ready is the most comprehensive set of downscaled climate projections data ever available in South Australia. The data can be used in future planning decisions. For example, to ensure that planned future infrastructure such as roads, bridges, farm dams and mine tailings dams, are designed to take into account; the impacts of climate change enable water resource and catchment managers to assess the security of future water supplies and protect water supplies for all water users; and anticipate changes in extreme heat and fire risk to inform planning for South Australia's emergency, health and social services sectors.

\subsubsection{Stormwater Interventions - linking catchment actions to coastal water quality}

The government of South Australia is developing an Integrated Urban Water Management Plan (IUWMP) for Greater Adelaide that will embrace all available water sources including stormwater and wastewater. Currently, investment in stormwater and wastewater infrastructure is made or guided by state and local government agencies of South Australia. This does not currently include an evaluation of the relative effectiveness and efficiency of the investment (separately or in combination) in achieving goals such as water supply security, flood management and improved receiving water quality. In addition, there is a lack of understanding on catchment-scale implications of water sensitive urban design (WSUD) interim targets. While previous work has partially addressed some of the knowledge gaps more information is required to address the most efficient and cost effective way to manage stormwater and wastewater discharges to improve coastal water quality. This research has brought together the available information and tools to enable the assessment of stormwater interventions in the catchment to coastal water quality and other benefits.

These research investments are being drawn together in the peri-urban area north of Adelaide. This is a growing region for urban development, industry and agriculture. All require access to reliable, fit-for-purpose water supplies. The Goyder Institute is leading a program to coordinate the existing knowledge, including the latest science from the Goyder Institute's research portfolio and the specific water infrastructure projects undertaken by local authorities and state government. This coordination will bring together the best available assessment on the available quantity and quality of the northern Adelaide water resources including groundwater, surface water, stormwater and wastewater recycling, desalination, inter-basin transfers and projected demand to deliver an integrated water resource assessment now and into the fu-

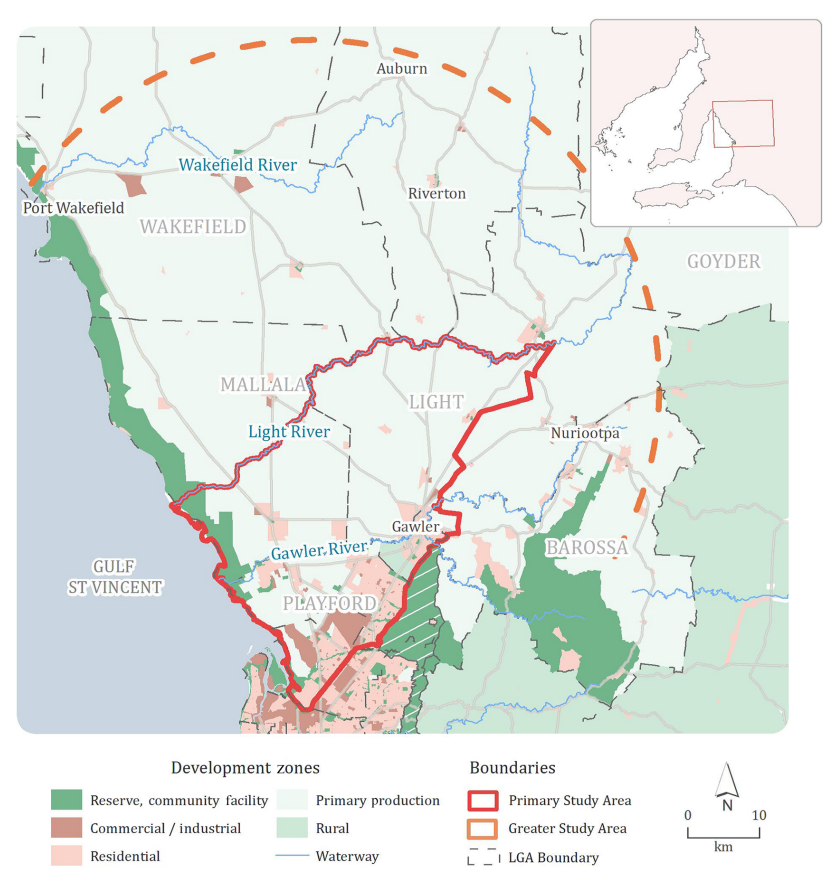

Figure 2. Proposed development region in Northern Adelaide Plains, South Australia.

ture to support sustainable development. Outcomes from two of the Goyder Institute projects are presented in relation to the development of the NAP region.

\section{Application of findings to Northern Adelaide Plains}

Outcomes from two projects as applied to the NAP region are presented below.

\subsection{Adelaide Plains groundwater}

The largest reserves of fresh groundwater in the Adelaide Plains are contained in the Tertiary $\mathrm{T} 1$ and $\mathrm{T} 2$ aquifers which extend from the Eden-Burnside Fault and Para Fault in the east up to an unknown distance offshore in the west (Gerges, 1999). These groundwater resources have been utilised since the start of the 20th century and continue to act as a vital water resource for Adelaide's industry, agriculture and horticulture, and recreational facilities. With growing pressures such as increasing groundwater demand and a changing climate, the longevity of these resources is a critical concern, which calls for effective groundwater management. In this context, a robust understanding of groundwater flow mechanisms is required.

A modelling platform was developed by RPS Aquaterra (Georgiou et al., 2011) for the South Australian Government Department of Environment Water and Natural Resources (DEWNR) and has recently been used to help manage the 


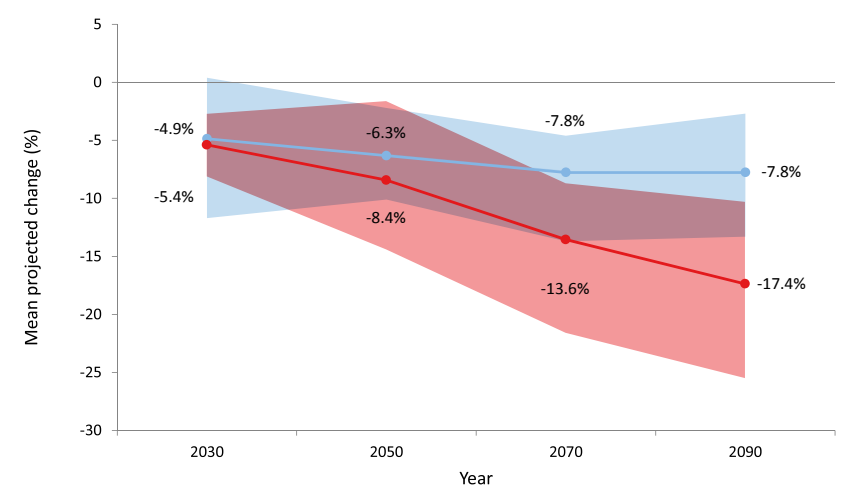

Figure 3. Predicted changes in average annual rainfall in the Adelaide Mt. Lofty Ranges region (from Goyder Institute for Water Research, 2015).

groundwater resources of the Adelaide Plains. However, the model showed some significant contradictions with the accepted conceptualization of the groundwater flow mechanisms in the region. Namely, diffuse recharge largely dominated the water budget (Georgiou et al., 2011). In contrast, diffuse recharge across the Adelaide Plains is believed to be insignificant, with recharge being mainly the result of infiltration from surface water features (Miles, 1952; Shepherd, 1975; Gerges, 1999). The model also showed groundwater flowing from the plains towards the hills along a significant portion of the eastern model boundary, especially in the NAP when groundwater should globally flow from the hills towards the plains. Furthermore, the model did not benefit from a number of modern techniques available for calibration.

This research showed that both river leakage flow and lateral flow contribute to groundwater flow mechanisms. Simulations also showed the observed widespread decline of potentiometric levels indicates that total pumping of groundwater is presently occurring at a rate that largely exceeds natural inflows, resulting in a strong decline in storage in the groundwater system and increased cross-formational flow. Furthermore, despite the fact that abstraction is largest from the T1 and T2 aquifers, most of the storage depletion occurs the Quaternary units which have relatively high groundwater salinity. Consequently, there is an increased risk in salinity in the Tertiary aquifers (Bresciani et al., 2015b), which could severely limit the crops able to be grown in the area.

The development of the groundwater flow and transport modelling platform will allow the groundwater supplies to be optimally managed to ensure there is not over-extraction and to minimise the salinisation of the water source.

\subsection{SA Climate Ready}

One of the key drivers affecting future water availability and hence development in South Australia will be climate change, which will place new pressures on water use and threaten supply. In 2011, the Goyder Institute commenced

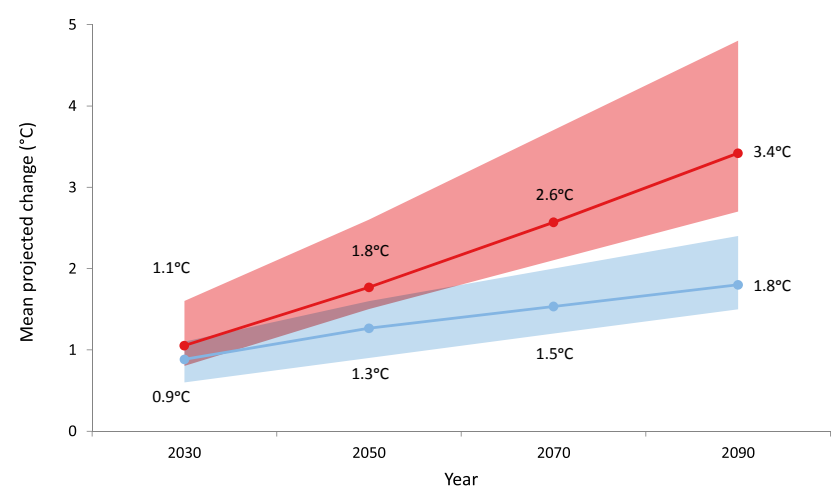

Figure 4. Predicted changes in average annual maximum temperature in the Adelaide Mt. Lofty Ranges region (from Goyder Institute for Water Research, 2015).

a project to develop downscaled climate change projections for South Australia, that is, possible future climates generated at a local scale. There are over 40 global climate models (GCMs) used by the Intergovernmental Panel on Climate Change (IPCC) for generating climate projections. The Goyder Institute identified a subset of these GCMs based on their ability to reproduce the State's climate drivers such as the Indian Ocean Dipole and the El Niño-Southern Oscillation (ENSO). This sub-set of GCMs were then used to generate climate projections at a local scale - providing the best available science to ensure that South Australia is Climate Ready. SA Climate Ready is the most comprehensive set of downscaled climate projections data ever available in South Australia. Data is available for six climate variables (rainfall, temperature maximum, temperature minimum, areal potential evapotranspiration, solar radiation, vapour pressure deficit), using two emission scenarios (intermediate and high "representative concentration pathways") through to 2100 .

Regional downscaling for the Adelaide and Mt. Lofty Ranges region includes the NAP area that is planned for future expansion. Climate modelling suggests that average annual rainfall in the region could decline by up to 7.8 to $17.4 \%$ by the end of the 21 st century (Fig. 3). In addition, average annual maximum temperatures have been modelled to increase by 1.8 to $3.4^{\circ} \mathrm{C}$ (Fig. 4). The greatest decline in average annual future rainfall is projected in spring which coincides with warming in spring (Goyder Institute for Water Research, 2015). This projected drier and warmer spring potentially may have implications with regard current agricultural practices in the NAP where horticultural and broadacre crops rely on spring rains to maximise yields. The type of crops grown and the growing season may have to be reassessed based on projected climate changes in the region. In addition alternative sources of water for crop production may need to be identified in the event of reduction in surface water. 


\section{Conclusions}

The findings from projects from the Goyder Institute for Water Research are providing valuable data and models for planning future development in the NAP region. In addition the research will allow better integration of current available water sources and projections of the effect of increasing demands on these sources.

\section{Data availability}

The Goyder Institute projects have generated substantial data sets. Generally the datasets have been stored with the research partner that was responsible for the project work. However, these data sets are described on the Goyder Institute for Water Research page at the Australian National Data Service (ANDS) http://researchdata.ands.org.au/ goyder-institute-water-research/267198/ (Piantadosi et al., 2015; Banks et al., 2015). Further contact details for accessing the data or contacting the key researchers involved are provided at this site. Model Metadata Templates have also been developed for a number of models modified or developed within Goyder Institute projects. These Templates are available at http://goyderinstitute.org/index.php?id=67 (Charles, 2014a, b; Bresciani, 2015).

Acknowledgements. The authors thank their colleagues from the Goyder Institute for Water Research partners, namely CSIRO, University of Adelaide, University of South Australia, Flinders University and the South Australian Government for the research outcomes that have contributed to this paper.

\section{References}

Anon: Virginia Pipeline Committee, Bolivar-Virginia Reuse Project, Roger Stokes and Associates, 1995.

Banks, E., Batelaan, O., Batlle Aguilar, J., Kozuskanich, J. C., and Post, V. E.: Adelaide Plains Groundwater Model 2015: Assessment of Adelaide Plains Groundwater Resources, available at: https://researchdata.ands.org.au/ adelaide-plains-groundwater-groundwater-resources/638490/ ?refer_q=, 2015.

Bresciani, E.: Adelaide Plains Groundwater Model 2015, available at: http://www.goyderinstitute.org/uploads/Adelaide_Plains_ Groundwater_Model_Template_v5.pdf, 2015.

Bresciani, E., Batelaan, O., Banks, E. W., Barnett, S. R., BatlleAguilar, J., Cook, P. G., Costar, A., Cranswick, R. H., Doherty, J., Green, G., Kozuskanich, J., Partington, D., Pool, M., Post, V. E. A., Simmons, C. T., Smerdon, B. D., Smith, S. D., Turnadge, C., Villeneuve, S., Werner, A. D., White, N. and Xie, Y.: Assessment of Adelaide Plains Groundwater Resources: Summary Report, Goyder Institute for Water Research Technical Report Series No. 15/31, Adelaide, South Australia, available at: http://www.goyderinstitute.org/index.php?id=20 (last access: August 2016), 2015a.
Bresciani, E., Partington, D., and Xie, Y.: Adelaide Plains groundwater model, available at: http://www.goyderinstitute.org/ uploads/Adelaide_Plains_Groundwater_Model_Template_v5. pdf (last access: August 2016), 2015 b.

Charles, S.: An implementation of a multivariate daily weather generator, available at: http://www.goyderinstitute.org/uploads/ ClimateChange_Multivariate_Daily_Weather_Generator.pdf, 2014a.

Charles, S.: MVNHMM Multi-Variate Non-homogeneous Hidden Markov Model, available at: http://www.goyderinstitute.org/ uploads/ClimateChange_MVNHMM.pdf, 2014b.

CSIRO: Climate change in Australia, Technical Report, available at: http://www.climatechangeinaustralia.gov.au (last access: August 2016), 2007.

Georgiou, J., Stadter, M., and Purczel, C.: Adelaide Plains groundwater flow and solute transport model, available at: http://www.goyderinstitute.org/uploads/Adelaide_Plains_ Groundwater_Model_Template_v5.pdf (last access: August 2016), 2011.

Gerges, N. Z.: The Geology and Hydrogeology of the Adelaide Metropolitan Area Volume 1 and Volume 2, PhD thesis, Flinders University, South Australia, 1999.

Government of South Australia, Department of Planning and Local Government: Population Projections for South Australia and Statistical Divisions, 2011-41, September, available at: http://www.dpti.sa.gov.au/_data/assets/pdf_file/0007/177937/ Population_Projections_SA_SD_2011_41_Report.pdf (last access: August 2016), 2015.

Goyder Institute for Water Research: SA Climate Ready Regional Summaries, Adelaide Mount Lofty Ranges, available at: http://www.goyderinstitute.org/uploads/Fact\%20Sheets/ SA\%20Climate\%20Ready\%20Regional\%20Summary\%20-\% 20AMLR.pdf (last access: August 2016), 2015.

Piantadosi, J., Beecham, S., Kamruzzaman, M., Boland, J., and Fleming, N.: Development of an agreed set of climate projectsions for South Australia, available at: https://researchdata.ands. org.au/development-an-agreed-south-australia/625589/?refer_ $\mathrm{q}=, 2015$.

Miles, K. R.: Geology and underground water resources of the Adelaide Plains area, Department of Mines: Adelaide, 1952.

Shepherd, R. G.: Northern Adelaide Plains groundwater study, Stage II, 1968-74, Department of Mines South Australia, Report Book 75/38, 1975.

Stevens, D.: Sustainable use of recycled water for horticultural irrigation on the Northern Adelaide Plains, Horticulture Australia Ltd Technical Report Project VG97081, available at: http://ausveg.com.au/intranet/technical-insights/docs/ VG97081.pdf (last access: August 2016), 2004. 